\title{
The Urate-lowering Efficacy and Safety of Febuxostat in Korean Patients with Gout
}

\author{
Sung Hwan Park ${ }^{1}$, Yeong Wook Song ${ }^{2}$, Won Park ${ }^{3}$, Eun Mi Koh ${ }^{4}$, Bin Yoo ${ }^{5}$ Soo Kon Lee \\ Dae Hyun Yoo ${ }^{7}$, Yun Jong Lee ${ }^{8}$, Hyun Ah Kim ${ }^{9}$, Hyo Jin Choi ${ }^{10}$, Ho Youn Kim ${ }^{1}$, Hyong Gi Jung ${ }^{11}$ \\ Department of Internal Medicine, Seoul St. Mary's Hospital ${ }^{1}$, Department of Internal Medicine, Seoul National \\ University Hospital ${ }^{2}$, Seoul, Department of Internal Medicine, Inha University Hospital ${ }^{3}$, Incheon, Department of \\ Internal Medicine, Samsung Medical Center, Sungkyunkwan University School of Medicine ${ }^{4}$, Department of Internal \\ Medicine, Asan Medical Center, University of Ulsan College of Medicine ${ }^{5}$, Department of Internal Medicine, \\ Severance Hospital ${ }^{6}$, Department of Medicine, Hanyang University Medical Center ${ }^{7}$, Seoul, Department of Internal \\ Medicine, Seoul National University Bundang Hospital ${ }^{8}$, Seongnam, Department of Internal Medicine, Hallym \\ University Sacred Heart Hospital ${ }^{9}$, Pyeongchon, Department of Internal Medicine, Gachon Medical School Gil \\ Medical Center ${ }^{10}$, Incheon, Department of Biostatistics, Seo Kyeong University ${ }^{11}$, Seoul, Korea
}

Objective. To compare the urate-lowering efficacy and the safety of febuxostat, allopurinol and placebo in Korean patients with gout for 4 weeks.

Methods. Subjects $(\mathrm{n}=182)$ with gout were randomized to febuxostat $(40,80,120 \mathrm{mg}$ ), allopurinol $300 \mathrm{mg}$, or placebo group. The primary end point was the proportion of subjects whose serum urate concentration fell to less than 6.0 mg/dL after the 4-week treatment.

Results. The primary end point was reached at $25.7 \%$, $80.0 \%$ and $83.3 \%$ of patients receiving 40,80 and $120 \mathrm{mg}$ of febuxostat, respectively, $58.3 \%$ of those receiving $300 \mathrm{mg}$ of allopurinol and none of the placebo $(p<0.001$ : each febuxostat dose or allopurinol group versus placebo group, $p=0.0484$ and $p=0.0196$ : febuxostat 80 and $120 \mathrm{mg}$ compared

\section{Introduction}

Febuxostat is a new uric acid synthesis inhibitor. It is a 2 -arylthiazole derivative, which was chemically engineered, as a novel xanthine oxidase/xanthine dehydrogenase (XO) inhibitor. Febuxostat is being used for the management of hyperuricemia in patients with gout (1-3), and is already approved for marketing in major countries including EU, USA and Japan.

For over 30 years, allopurinol is the only uric acid synthesis with allopurinol, respectively). The number and proportion of subjects who developed adverse events (AEs) were 13 subjects $(37 \%), 14(39 \%)$ and $18(50 \%)$ in the febuxostat of 40 , 80 and $120 \mathrm{mg}$ group, respectively, $21(57 \%)$ in the allopurinol $300 \mathrm{mg}$ group and $17(46 \%)$ in the placebo group. No statistically significant differences in the incidence rates of adverse events were observed between the groups. There was no significant difference in gout flare-up incidence. Conclusion. Febuxostat, $80 \mathrm{mg}$ or $120 \mathrm{mg}$, was more effective than allopurinol $(300 \mathrm{mg})$ or placebo, when lowering the serum urate. The safety of febuxostat and allopurinol was comparable.

Key Words. Gout, Febuxostat, Urate-lowering efficacy, Korean patients

inhibitor that is being used for hyperuricemia and gout. Uric acid is the last product of purine metabolism, by a process catalyzed by $\mathrm{XO}$, through which, subsequent intermediate products are generated from hypoxanthine to xanthine, and finally to uric acid. Allopurinol, whose chemical structure is similar to that of purine, acts as an inhibitor of xanthine oxidase. Oxipurinol, a major metabolite of allopurinol, also inhibits other enzymes in the process of purine metabolism $(4,5)$. Oxipurinol is mainly ex-

\footnotetext{
<Received: November 27, 2012, Revised (1st: January 7, 2013, 2nd: April 9, 2013), Accepted : April 9, 2013>

Corresponding to : Yeong Wook Song, Department of Internal Medicine, Seoul National University Hospital, 101, Daehak-ro, Jongno-gu, Seoul 110-744, Korea. E-mail : ysong@snu.ac.kr 
creted via the urine and its excretion is delayed in patient with renal dysfunction. Continued high serum level of oxipurinol in patients with renal problems is worrisome (5). Febuxostat is a new uric acid synthesis inhibitor, which has a totally different chemical structure from that of allopurinol. It selectively inhibits $\mathrm{XO}$, without acting on the other major enzymes that are related to purine metabolism. It has been confirmed to be a potent selective xanthine oxidase/xanthine dehydrogenase (XO) inhibitor in vitro and have strong effects on lowering the serum and urine uric acid concentrations in animals, such as rats and chimpanzees $(6,7)$. Several randomized controlled clinical trials (RCTs) have shown febuxostat's (in daily doses from 80 to $240 \mathrm{mg}$ ) superiority in urate-lowering efficacy, when compared to that of placebo or allopurinol at $300 \mathrm{mg}$ daily. Moreover, febuxostat was more efficacious than allopurinol and was equally safe for subjects with hyperuricemia and gout complicated by mild and moderate renal impairment (8-11). The small number of severe cardiovascular (CV) AEs, was encountered in febuxostat/allopurinol comparative RCTs. However safety of febuxostat and allopurinol, including CV safety, was comparable at doses of $40 \mathrm{mg}$ or $80 \mathrm{mg}$ of febuxostat (8).

In a phase II study involving gout patients, the proportion of subjects achieving a serum urate concentration of $<6.0$ $\mathrm{mg} / \mathrm{dL}$, after 4 weeks of treatment, with febuxostat $40 \mathrm{mg}$ QD, febuxostat $80 \mathrm{mg}$ QD and febuxostat $120 \mathrm{mg}$ QD were 56\%, $76 \%$ and $94 \%$, respectively (12). The mean serum uric acid reduction from baseline at day 28 was $2 \%$ in the placebo group, $37 \%$ in the $40 \mathrm{mg}$ febuxostat group, $44 \%$ in the 80 $\mathrm{mg}$ febuxostat group and 59\% in the $120 \mathrm{mg}$ febuxostat group. The difference in urate level reduction was statistically significant between the placebo group and each of the febuxostat treatment groups (febuxostat $40 \mathrm{mg}, 80 \mathrm{mg}$ and $120 \mathrm{mg}$ ). These previous results suggested that a 4 -week trial is acceptable in demonstrating the urate lowering efficacy of febuxostat.

This was a randomized, multi-centered, double-blinded, allopurinol-controlled, placebo-controlled study, which is undertaken to evaluate the urate-lowering effect of febuxostat in the Korean population with hyperuricemia and gout.

\section{Materials and Methods}

\section{Study population}

Subjects with the age of 18 to 85 years, with a diagnosis of gout (based on the preliminary criteria of the American College of Rheumatology for acute arthritis of gout (13)) were enrolled in the study. Serum uric acid of $\geq 8.0 \mathrm{mg} / \mathrm{dL}$ and serum creatinine of $\leq 1.5 \mathrm{mg} / \mathrm{dL}$ were eligible for the study.
Exclusion criteria included; subjects with hypersensitivity to allopurinol, thiazide diuretic therapy, aspirin $>325 \mathrm{mg} /$ day, prednisolone $>10 \mathrm{mg} /$ day, alcohol intake $\geq 14$ drinks/week, other urate-lowering therapy, and hepatic dysfunction (both alanine aminotransferase (ALT) and aspartate aminotransferase (AST) $>1.5$ times the upper limit of normal).

\section{Study method}

This study was conducted at 10 centers in Korea and was approved from the institutional review boards of each respective institution based on the Declaration of Helsinki. All subjects gave written informed consent.

Subjects that passed the screening evaluation were then randomly assigned to one of the five treatment regimens; febuxostat $40 \mathrm{mg}, 80 \mathrm{mg}, 120 \mathrm{mg}$, placebo or allopurinol $300 \mathrm{mg}$ QD based on their serum urate level at baseline (1) $\geq 8$ $\mathrm{mg} / \mathrm{dL}, \quad<9 \mathrm{mg} / \mathrm{dL}, 2) \geq 9 \mathrm{mg} / \mathrm{dL}, \quad<10 \mathrm{mg} / \mathrm{dL}, 3) \geq 10$ $\mathrm{mg} / \mathrm{dL}$ ). The stratified randomization was used to keep the balance of serum urate concentration between groups and done by the central coordinator to maintain the blindness. The patient visiting schedule was as follows; day -14 or day -1 screening visit (day -14 for subjects taking allopurionol or uricosuric agents prior to this study, or Day -1 for subjects not receiving allopurionol or uricosuric agents), day -1 visit, day 1 visit and the 28-day treatment period. Colchicine $0.6 \mathrm{mg}$ QD was given to minimize the risk of gout flare-ups, acute gout response manifesting red, hot or swollen joint with pain, during the washout/run-in period, and during the double blind study period. The medication which could impact on the serum urate concentration and interact with the study medication was prohibited; chronic use ( $>100$ consecutive days) of NSAIDs, salicylate-containing medication, probenecid, benzbromarone, thiazide diuretics, predisone, azathioprine, mercaptopurine, dicumarol, cyclophospamide, trimethoprim-sulfamethoxazole and so on. Low dose aspirin $(\leq 325 \mathrm{mg} /$ day $)$ and acetaminophen were allowed as required.

\section{Efficacy endpoint}

The primary end point was the proportion of subjects whose serum urate concentration fell to less than $6.0 \mathrm{mg} / \mathrm{dL}$ after 4 weeks of treatment. The secondary end point was the percent reductions in serum urate levels from the baseline to the end of the study (day 28).

\section{Demographic information and medical history}

All data were collected from the patients regarding body mass index (BMI), alcohol use and coexisting conditions, according to each treatment group. 


\section{Statistical analysis}

Efficacy analysis was based on the intention to treat (ITT) population. The last-observation-carried-forward (LOCF) imputation method was used for the missing data. The primary endpoint, the proportion of the subjects, whose serum urate concentration that fell to less than $6.0 \mathrm{mg} / \mathrm{dL}$ after the 4-week treatment, was compared across the febuxostat groups, the placebo group and the allopurinol group using a chi-square or fisher's exact test. The three febuxostat treatment groups (40 mg QD, $80 \mathrm{mg}$ QD, and $120 \mathrm{mg}$ QD) and the placebo treatment group were compared using the Bonferroni multiple comparison. The percent reductions in serum urate levels from the baseline at each visit, within each treatment group, were analyzed by analysis of covariance (ANOVA) and re- peated measure ANCOVA was used for the comparison between each of the treatment group.

In compliance with the Medical Dictionary for Regulatory Activities (MedDRA) coding dictionary, the number of subjects, who experienced treatment-emergent adverse events (TEAEs) and the percentages, were presented. Betweengroups comparisons of TEAE incidence were conducted, using a chi-square test or Fisher's exact test. The frequency of subjects requiring treatment of gout flare-up was compared among the treatment groups, using a chi-square test or Fisher's exact test.

Baseline demographics were compared by ANOVA or Kruskal Wallis test for continuous variables and by chisquare test or Fisher's exact test for categorical variables.

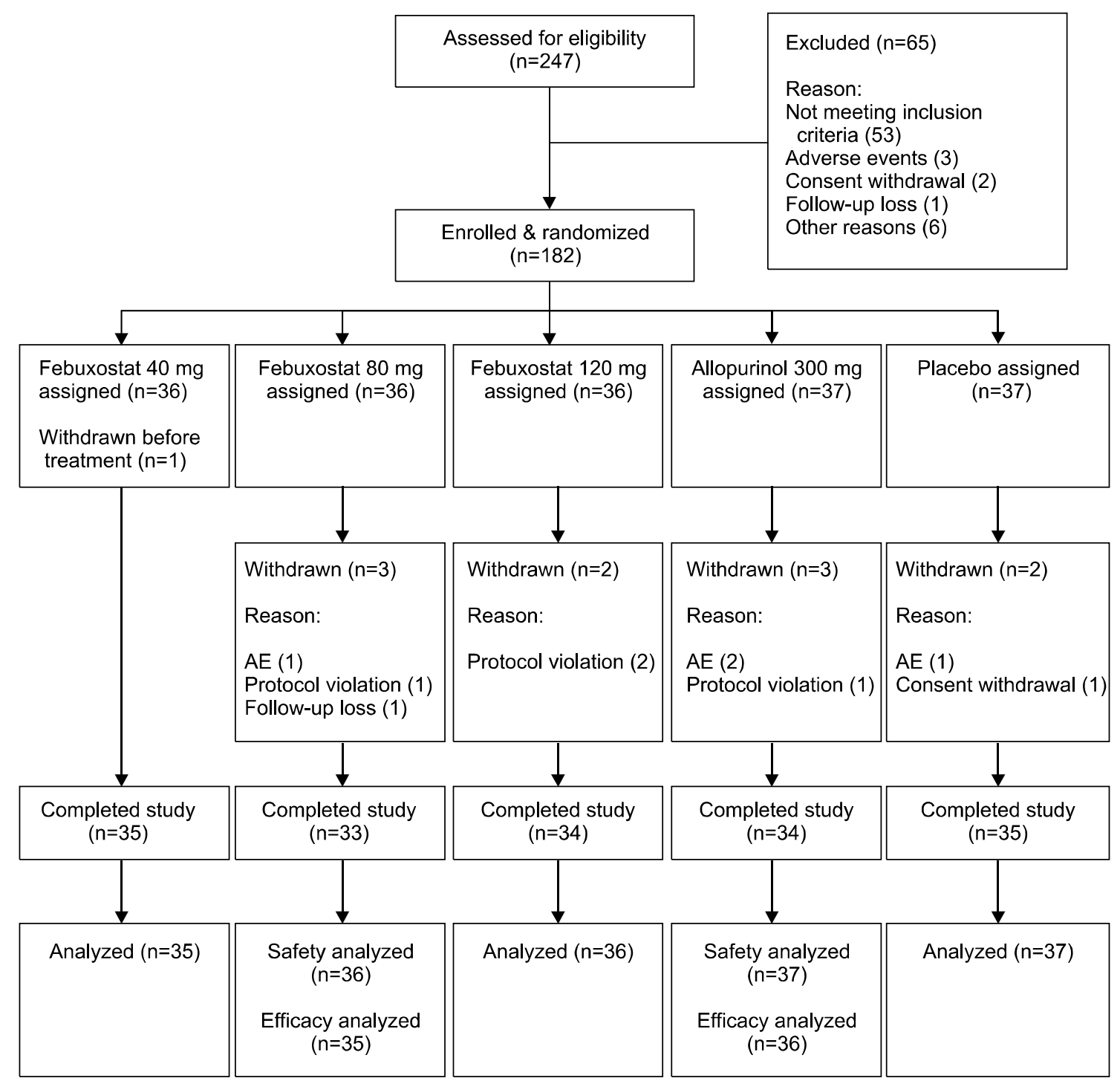

Figure 1. Flow chart of the patient allocation. 


\section{Results}

\section{Subject demographics and disposition}

Of the 247 subjects screened, 182 were randomly assigned to the different treatment groups (Figure 1). All subjects were male. The mean age $( \pm \mathrm{SD})$ was $50.0( \pm 11.6)$ years old. No statistically significant difference was found in the age distribution between the groups $(\mathrm{p}=0.6978)$. There was also no statistically significant difference in BMI, smoking, drinking history and coexisting conditions between the groups. There were no significant differences across the treatment groups in the baseline concentration of serum uric acid (Table 1).

Withdrawal rates were similar in all the five groups. One subject randomized to febuxostat $40 \mathrm{mg}$ was excluded from the ITT efficacy analysis, due to the consent withdrawal prior of starting the medication regimen. Two subjects ( 1 each in the febuxostat $40 \mathrm{mg}$ and allopurinol $300 \mathrm{mg}$ ), who did not have evaluable results of the serum urate level, were excluded from the ITT efficacy analysis.

\section{Efficacy analyses}

Primary efficacy endpoint: The proportion of subjects with serum urate concentration falling to less than $6.0 \mathrm{mg} / \mathrm{dL}$, after the 4 -week treatment, was $25.7 \%$ for patients receiving $40 \mathrm{mg}$ of febuxostat, $80.0 \%$ for those receiving $80 \mathrm{mg}$ of febuxostat, $83.3 \%$ for those receiving $120 \mathrm{mg}$ of febuxostat, and $58.3 \%$ for these receiving $300 \mathrm{mg}$ of allopurinol $(\mathrm{p}<0.001$ when comparing each febuxostat or allopurinol group with the pla- cebo group).

Using the allopurinol $300 \mathrm{mg}$ group as the reference, for which the febuxostat $40 \mathrm{mg}$ showed lower response rate $(\mathrm{p}=0.0054)$. However the febuxostat $80 \mathrm{mg}$ and febuxostat 120 $\mathrm{mg}$ groups showed higher response rates $(\mathrm{p}=0.0484, \mathrm{p}=0.0196$ respectively, Figure 2).

Secondary efficacy endpoint: The percent reduction in the serum urate levels from the baseline at the end of the study (day

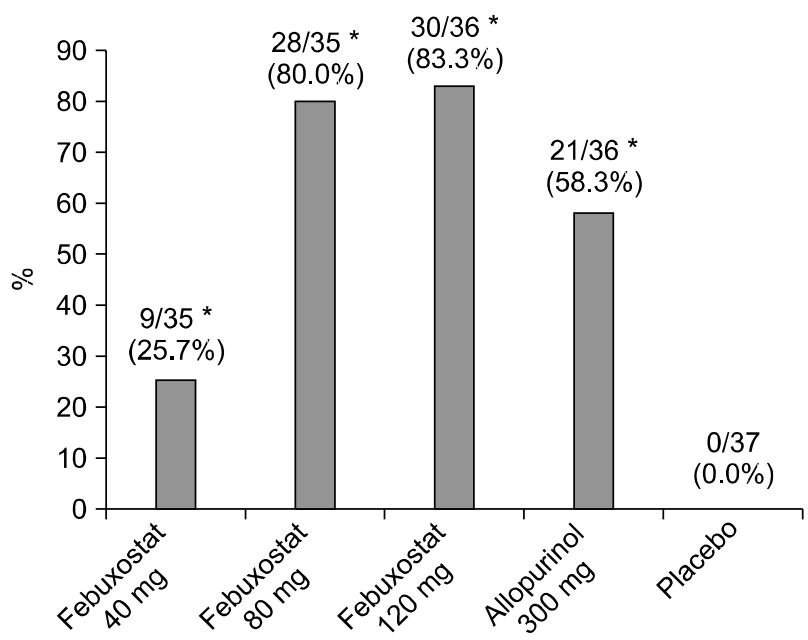

Figure 2. The proportions of subjects with serum urate levels falling to $<6.0 \mathrm{mg} / \mathrm{dL}$ after the 4-week treatment. ${ }^{*} \mathrm{p}<0.0001$ vs. placebo, Febuxostat $40 \mathrm{mg}, 80 \mathrm{mg}, 120 \mathrm{mg}$ vs. allopurinol, $\mathrm{p}=0.0054,0.0484,0.0196$ respectively. $\mathrm{p}$-value by Fisher's exact test or chi-square test.

Table 1. Baseline characteristics of the gout patients according to the treatment groups

\begin{tabular}{|c|c|c|c|c|c|c|}
\hline Characteristic & $\begin{array}{c}\text { Febuxostat } \\
40 \mathrm{mg}(\mathrm{n}=35)\end{array}$ & $\begin{array}{c}\text { Febuxostat } \\
80 \mathrm{mg}(\mathrm{n}=36)\end{array}$ & $\begin{array}{c}\text { Febuxostat } \\
120 \mathrm{mg}(\mathrm{n}=36)\end{array}$ & $\begin{array}{l}\text { Allopurinol } \\
300 \mathrm{mg}(\mathrm{n}=37)\end{array}$ & $\begin{array}{l}\text { Placebo } \\
(\mathrm{n}=37)\end{array}$ & p-value \\
\hline Age (mean \pm SD years) & $49.6 \pm 11.9$ & $48.9 \pm 12.3$ & $51.2 \pm 9.9$ & $48.6 \pm 11.8$ & $51.8 \pm 12.4$ & $0.6978^{*}$ \\
\hline BMI & $26.3 \pm 3.5$ & $25.1 \pm 2.8$ & $25.8 \pm 2.1$ & $25.7 \pm 3.3$ & $25.7 \pm 3.1$ & $0.5421^{*}$ \\
\hline Alcohol use & $20(57.1)$ & $24(66.7)$ & $28(77.8)$ & $26(70.3)$ & $28(75.7)$ & $0.3419^{\dagger}$ \\
\hline Tobacco use & $9(25.7)$ & $13(36.1)$ & $12(33.3)$ & $17(46.0)$ & $14(37.8)$ & $0.2344^{\dagger}$ \\
\hline Coexisting conditions & & & & & & $0.9934^{\dagger}$ \\
\hline Diabetes mellitus & $1(2.9)$ & $0(0.0)$ & $0(0.0)$ & $2(5.4)$ & $1(2.7)$ & \\
\hline Dyslipidemia $^{\dagger}$ & $4(11.4)$ & $3(8.3)$ & $5(13.9)$ & $5(13.5)$ & $10(27.0)$ & \\
\hline Hypertension & $11(31.4)$ & $9(25.0)$ & $8(22.2)$ & $18(48.7)$ & $12(32.4)$ & \\
\hline Baseline serum creatinine & $1.2 \pm 0.1$ & $1.2 \pm 0.2$ & $1.2 \pm 0.1$ & $1.2 \pm 0.1$ & $1.2 \pm 0.1$ & $0.3081^{*}$ \\
\hline $\begin{array}{l}\text { Baseline serum urate concentration } \\
(\mathrm{mean} \pm \mathrm{SD} \mathrm{mg} / \mathrm{dL})\end{array}$ & $9.7 \pm 1.1$ & $9.7 \pm 1.1$ & $9.5 \pm 1.0$ & $9.6 \pm 1.0$ & $9.8 \pm 1.2$ & $0.8230^{*}$ \\
\hline$\geq 8 \mathrm{mg} / \mathrm{dL},<9 \mathrm{mg} / \mathrm{dL}$ & $9(25.7)$ & $10(27.8)$ & $10(27.8)$ & $10(27.0)$ & $11(29.7)$ & \\
\hline$\geq 9 \mathrm{mg} / \mathrm{dL},<10 \mathrm{mg} / \mathrm{dL}$ & $16(45.7)$ & $16(44.4)$ & $16(44.4)$ & $16(43.2)$ & $16(43.2)$ & $1.0000^{\dagger}$ \\
\hline$\geq 10 \mathrm{mg} / \mathrm{dL}$ & $10(28.6)$ & $10(27.8)$ & $10(27.8)$ & $11(29.7)$ & $10(27.0)$ & \\
\hline Previous urate-lowering therapy & & & & & & $0.9678^{\dagger}$ \\
\hline Allopurinol & $18(51.4)$ & $21(58.3)$ & $19(52.7)$ & $21(56.8)$ & $19(51.6)$ & \\
\hline Benzbromarone & $2(2.7)$ & $3(8.3)$ & $3(8.3)$ & $0(0.0)$ & $3(8.1)$ & \\
\hline
\end{tabular}

BMI: body mass index. ${ }^{*}$ p-value by ANOVA or Kruscal Wallis test, ${ }^{\dagger}$ p-value by Fisher's exact test or chi-square test, ${ }^{\ddagger}$ including hypercholesterolemia and hypertriglyceridemia. 
Table 2. Percent reduction of serum urate concentration from baseline at final visit - ITT population

\begin{tabular}{|c|c|c|c|c|}
\hline \multicolumn{2}{|c|}{ Treatment group } & \multirow{2}{*}{$\begin{array}{c}\text { Mean } \pm \text { SD }(\mathrm{mg} / \mathrm{dL}) \\
9.7 \pm 1.1\end{array}$} & \multirow{2}{*}{ p-value (vs. placebo) } & \multirow{2}{*}{ p-value (vs. allopurinol) } \\
\hline Febuxostat $40 \mathrm{mg}(\mathrm{N}=35)$ & Baseline & & & \\
\hline & Day 14 & $6.4 \pm 1.0$ & & \\
\hline & Day 28 & $6.5 \pm 1.2$ & & \\
\hline & Percent reduction $(\%)$ & $-32.4 \pm 12.4$ & $<.0001$ & 0.0116 \\
\hline \multirow[t]{4}{*}{ Febuxostat $80 \mathrm{mg}(\mathrm{N}=35)$} & Baseline & $9.7 \pm 1.1$ & & \\
\hline & Day 14 & $4.7 \pm 0.9$ & & \\
\hline & Day 28 & $4.9 \pm 1.5$ & & \\
\hline & Percent reduction $(\%)$ & $-49.0 \pm 12.8$ & $<.0001$ & 0.0070 \\
\hline \multirow[t]{4}{*}{ Febuxostat $120 \mathrm{mg} \quad(\mathrm{N}=36)$} & Baseline & $9.5 \pm 1.0$ & & \\
\hline & Day 14 & $4.3 \pm 1.8$ & & \\
\hline & Day 28 & $4.2 \pm 1.9$ & & \\
\hline & Percent reduction $(\%)$ & $-55.7 \pm 20.4$ & $<.0001$ & $<.0004$ \\
\hline \multirow[t]{4}{*}{ Allopurinol $300 \mathrm{mg} \quad(\mathrm{N}=36)$} & Baseline & $9.6 \pm 1.0$ & & \\
\hline & Day 14 & $5.8 \pm 1.3$ & & \\
\hline & Day 28 & $5.8 \pm 1.5$ & & \\
\hline & Percent reduction $(\%)$ & $-40.4 \pm 13.5$ & $<.0001$ & - \\
\hline \multirow[t]{4}{*}{ Placebo $(\mathrm{N}=37)$} & Baseline & $9.8 \pm 1.2$ & & \\
\hline & Day 14 & $9.8 \pm 1.5$ & & \\
\hline & Day 28 & $9.8 \pm 1.5$ & & \\
\hline & Percent reduction $(\%)$ & $0.9 \pm 13.6$ & - & - \\
\hline
\end{tabular}

p-value by t-test. ITT: intention to treat.

28) were analyzed. The percent reduction in the serum urate concentration from the baseline at 28 days were $32.4 \pm 12.4 \%$ in patients receiving $40 \mathrm{mg}$ of febuxostat, $49.0 \pm 12.8 \%$ in those receiving $80 \mathrm{mg}$ of febuxostat, $55.7 \pm 20.4 \%$ in those receiving $120 \mathrm{mg}$ of febuxostat, $40.4 \pm 13.5 \%$ in those receiving $300 \mathrm{mg}$ of allopurinol and $0.9 \pm 13.6 \%$ in those receiving placebo ( $\mathrm{p}<0.001$ by $\mathrm{t}$-test when comparing each febuxostat or allopurinol group with the placebo group) (Table 2). As the dose of the febuxostat being administered increased, the percent reduction in the serum urate concentration tended to be increased, but it was not statistically significant.

Adverse events (AEs): The incidence of AEs was similar among the five treatment groups (Table 3). AEs occurring in $>5 \%$ of the subjects, in each treatment group, are listed in Table 3. The majority of AEs were mild or moderate in severity. The frequency of abnormal liver function tests $(\geq 2.0$ times the upper limits of normal) between the groups were similar (Table 4).

The results of the laboratory test, vital signs and electrocardiogram did not show any significant difference and the most of subjects showed the finding within the normal range.

There were 4 cases in which the patients were withdrawn, due to adverse events.

Serious adverse events: One of three SAEs, acute pancreatitis, judged as related to the investigational drug occurred in the allopurinol $300 \mathrm{mg}$ group. The other two cases, renal cell carcinoma and coronary artery disease, were considered as unlikely related to the investigational drug.

Gout flare-ups: Gout flare-up appeared in 1 subject (2.86\%) in the febuxostat $40 \mathrm{mg}$ group, 3 subjects $(8.33 \%)$ in the febuxostat $120 \mathrm{mg}$ group, 2 subjects $(5.41 \%)$ in the allopurinol $300 \mathrm{mg}$ group and 1 subject $(2.70 \%)$ in the placebo group. No subject developed gout flare-up in the febuxostat $80 \mathrm{mg}$ group. There was no significant difference in the incidence of gout flare-up between each treatment group and the placebo group. Dose-dependent gout flare-ups did not occur in the febuxostat group (Figure 3).

\section{Discussion}

Febuxostat is a novel non-purine, selective inhibitor of xanthine oxidase. This drug was developed to treat hyperuricemia and gout (4-6). Febuxostat is being used for the management of hyperuricemia in patients with gout and has already been approved for marketing in major countries, including EU, 
Table 3. Adverse events occurring $>5 \%$ of subjects according to each treatment group

\begin{tabular}{|c|c|c|c|c|c|c|}
\hline & $\begin{array}{c}\text { Febuxostat } \\
40 \mathrm{mg}(\mathrm{n}=35)\end{array}$ & $\begin{array}{c}\text { Febuxostat } \\
80 \mathrm{mg}(\mathrm{n}=36)\end{array}$ & $\begin{array}{c}\text { Febuxostat } \\
120 \mathrm{mg}(\mathrm{n}=36)\end{array}$ & $\begin{array}{c}\text { Allopurinol } \\
300 \mathrm{mg}(\mathrm{n}=37)\end{array}$ & $\begin{array}{l}\text { Placebo } \\
(\mathrm{n}=37)\end{array}$ & p-value \\
\hline $\begin{array}{l}\text { Number of subjects with treatment emergent } \\
\text { adverse events (TEAEs, \%) }\end{array}$ & $13(37.1)$ & $14(38.9)$ & $18(50.0)$ & $21(56.78)$ & $17(46.0)$ & NS \\
\hline Arthralgia & 0 & $2(5.6)$ & $2(5.6)$ & 0 & 0 & \\
\hline Diarrhea & $2(5.7)$ & $2(5.6)$ & 0 & $1(2.7)$ & $1(2.7)$ & \\
\hline Urticaria & 0 & $1(2.8)$ & 0 & 0 & $2(5.4)$ & \\
\hline Alanine aminotransferase (ALT) increased ${ }^{*}$ & $7(20.0)$ & $3(8.3)$ & $5(13.9)$ & $4(10.8)$ & $1(2.7)$ & \\
\hline Aspartate aminotransferase (AST) increased ${ }^{\dagger}$ & $4(11.4)$ & $3(8.3)$ & $3(8.3)$ & $4(10.8)$ & $1(2.7)$ & \\
\hline Blood bilirubin increased ${ }^{\ddagger}$ & 0 & 0 & 0 & $2(5.4)$ & 0 & \\
\hline Hypertriglyceridaemia $^{\S}$ & $2(5.7)$ & $1(2.8)$ & $1(2.8)$ & $4(10.8)$ & $2(5.4)$ & \\
\hline Number of subjects with TEAEs related to drug & $7(20.0)$ & $7(19.4)$ & $7(19.4)$ & $13(35.1)$ & $6(16.2)$ & NS \\
\hline $\begin{array}{l}\text { Number of subjects with TEAEs } \\
\text { leading to withdrawal }\end{array}$ & 0 & $1(2.8)$ & 0 & $2(5.4)$ & $1(2.7)$ & NS \\
\hline Number of subjects with serious TEAEs & 0 & $1(2.8)$ & 0 & $1(2.7)$ & 0 & NS \\
\hline Coronary artery disease & & $1(2.8)$ & & & & \\
\hline Acute pancreatitis & & & & $1(2.7)$ & & \\
\hline Renal cell carcinoma stage I & & & & $1(2.7)$ & & \\
\hline
\end{tabular}

p-value, febuxostat or allopurinol vs. placebo. p-value by chi-square or Fisher's exact test. NS: not significant, *ALT increase above the upper normal limit, $43 \mathrm{IU} / \mathrm{L},{ }^{\dagger}$ AST increase above the upper normal limit, $38 \mathrm{IU} / \mathrm{L},{ }^{\ddagger}$ Bilirubin increase above the upper normal limit, $1.2 \mathrm{mg} / \mathrm{dL},{ }^{\S}$ Triglycerides increase above $200 \mathrm{mg} / \mathrm{dL}$.

Table 4. Liver function test abnormalities

\begin{tabular}{lcccccc}
\hline \hline & $\begin{array}{c}\text { Febuxostat } \\
40 \mathrm{mg}(\mathrm{n}=35)\end{array}$ & $\begin{array}{c}\text { Febuxostat } \\
80 \mathrm{mg}(\mathrm{n}=36)\end{array}$ & $\begin{array}{c}\text { Febuxostat } \\
120 \mathrm{mg}(\mathrm{n}=36)\end{array}$ & $\begin{array}{c}\text { Allopurinol } \\
300 \mathrm{mg}(\mathrm{n}=37)\end{array}$ & $\begin{array}{c}\text { Placebo } \\
(\mathrm{n}=37)\end{array}$ & $\begin{array}{c}\mathrm{p} \text {-value } \\
\text { ALT } \geq 2.0 \text { times the ULN }\end{array}$ \\
\hline AST $\geq 2.0$ times the ULN & 0 & $1(2.9)$ & $1(2.8)$ & $3(8.1)$ & 0 & NS \\
\hline
\end{tabular}

Values are the number of patients (\%). ALT: alanine aminotransferase, AST: aspartate aminotransferase, ULN: upper limit of normal. p-value, febuxostat or allopurinol vs. placebo, NS: not significant.

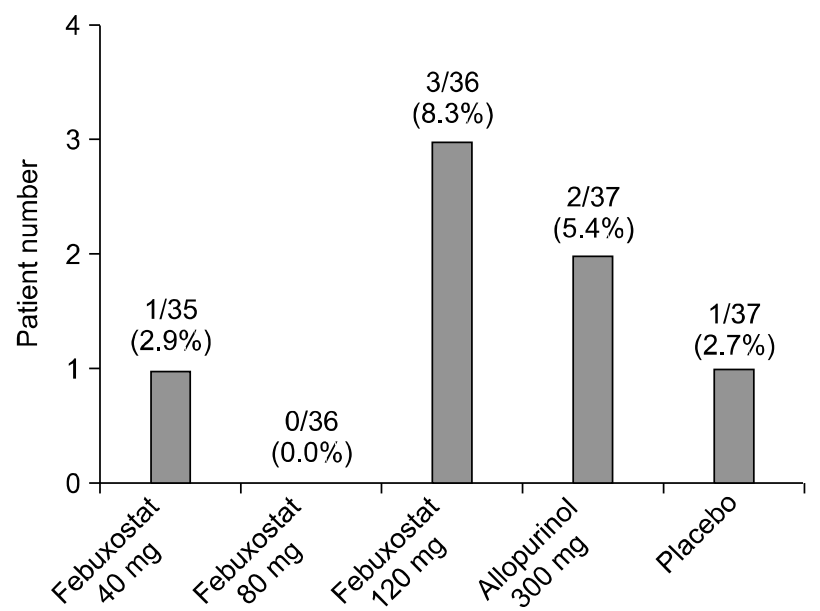

Figure 3. The frequency of subjects with gout flare-up. There were no significant differences in the incidence of gout flare-up between the groups during the treatment period $(p>0.05)$.

USA and Japan. This clinical study was conducted for the purpose of confirming the safety and efficacy of febuxostat in Korean patients with gout.
In line with previous RCT study (12), the urate lowering efficacy of febuxostat at daily dose of $40 \mathrm{mg}$ was higher than that of the placebo. Compared to the allopurinol $300 \mathrm{mg}$ group as a reference, the febuxostat $80 \mathrm{mg}$ and febuxostat $120 \mathrm{mg}$ groups showed better urate lowering efficacy $(p=0.0484$, $\mathrm{p}=0.0196$ ). The efficacy rate was lower in the febuxostat 40 mg group than the other groups, upon the proportion of subjects with the serum urate levels falling below $6.0 \mathrm{mg} / \mathrm{dL}$. However the percent reduction of serum urate with febuxostat $40 \mathrm{mg}$ group was about $32.4 \%$.

The meaningful effectiveness rapidly appeared at week 2 and was maintained until week 4 of treatment.

In this study, allopurinol $300 \mathrm{mg}$ was chosen for the reference since it was thought to be used by most subjects eligible for the study.

As in the previous study (12), the proportion of subjects whose serum urate concentration decreased to less than 6.0 $\mathrm{mg} / \mathrm{dl}$, after a 4 -week treatment, were $80.0 \%$ of patients receiving $80 \mathrm{mg}$ of febuxostat and $83.3 \%$ of those receiving 120 
mg of febuxostat in the present study. This result suggests the recommendation that if serum uric acid concentration does not decrease to less than $6 \mathrm{mg} / \mathrm{dL}$, after two weeks of $40 \mathrm{mg}$ of febuxostat given daily, the dosage can be increased to $80 \mathrm{mg}$ once daily. In the subgroup analysis of patients with uric acid, of more than $10 \mathrm{mg} / \mathrm{dL}$, the response rate tended to increase with higher dose of febuxostat (data not shown).

According to the prior report, dosage adjustments were not needed in the elderly patients or patients with mild or moderate renal or hepatic impairment (14).

The overall incidence of treatment related AEs occurring in $>5 \%$ of subjects in each group was similar for all the treatment groups, and most were mild to moderate in severity. The rate of discontinuation due to AEs was also similar for all treatment groups. A case of coronary artery disease was reported in the $80 \mathrm{mg}$ febuxostat group. This patient had a family history of ischemic heart disease and suffered from hypertension. Although he had no symptoms of coronary artery disease, he was evaluated by routine coronary CT on the 14th day of febuxostat. He was diagnosed with coronary 3 vessel disease and underwent heart bypass surgery. There was no complications after the surgery and he was discharged from the hospital one week later. The investigators assessed that this was unlikely related to the investigational drug.

In clinical practice, gout and hyperuricemia are strongly associated with cardiovascular disease and its risk factors. In this clinical trial, $45.6 \%$ of the enrolled subjects had risk factors for cardiovascular diseases. In addition, no significant difference between the treatment groups was observed in terms of cardiovascular AEs. Although AEs of increased ALT and AST were more frequent in the febuxostat and allopurinol groups than in the placebo group, the incidence rates in each group were comparable.

There was no significant difference in gout flare-up incidences between febuxostat or allopurinol groups and the placebo group. Dose-dependent gout flare-ups did not occur in the febuxostat group.

Allopurinol can cause a rare but fatal adverse event, such as allopurinol hypersensitivity and toxic epidermal necrolysis (15-17). Benzbromarone is also limitedly used because of its adverse effects of hepatotoxicity (15).

Febuxostat may be an alternative for patients with gout who are unable to take allopurinol due to hypersensitivity, intolerance, or lack of efficacy (3). Although the treatment period is as short as 28 days, the previous study (10) confirms that effectiveness appeared at week 2 and there were no significant differences for the reduction of serum urate levels among each visit after then. However, further study of long term treatment with febuxostat compared with allopurinol could ensure the effectiveness and safety of febuxostat in Korean patients.

\section{Conclusion}

Febuxostat is proven to lower serum urate levels in Korean patients with gout and the effectiveness of febuxostat $80 \mathrm{mg}$ and $120 \mathrm{mg}$ was superior to that of allopurinol. Febuxostat given daily at $40 \mathrm{mg}, 80 \mathrm{mg}$ and $120 \mathrm{mg}$ was safe and welltolerated. Febuxostat can be a new treatment option for patients with hyperuricemia and gout.

\section{Acknowledgements}

This study was sponsored by SK Chemicals Co. Ltd., Seongnam, Korea.

\section{References}

1. Terkeltaub R. Update on gout: new therapeutic strategies and options. Nat Rev Rheumatol 2010;6:30-8.

2. Terkeltaub R, Zelman D, Scavulli J, Perez-Ruiz F, Lioté F. Gout Study Group: update on hyperuricemia and gout. Joint Bone Spine 2009;76:444-6.

3. Chohan S, Becker MA. Update on emerging urate-lowering therapies. Curr Opin Rheumatol 2009;21:143-9.

4. Osada Y, Tsuchimoto M, Fukushima H, Takahashi K, Kondo S, Hasegawa M, et al. Hypouricemic effect of the novel xanthine oxidase inhibitor, TEI-6720, in rodents. Eur J Pharmacol 1993;241:183-8.

5. Khosravan R, Grabowski BA, Wu JT, Joseph-Ridge N, Vernillet L. Pharmacokinetics, pharmacodynamics and safety of febuxostat, a non-purine selective inhibitor of xanthine oxidase, in a dose escalation study in healthy subjects. Clin Pharmacokinet 2006;45:821-41.

6. Takano Y, Hase-Aoki K, Horiuchi H, Zhao L, Kasahara Y, Kondo S, et al. Selectivity of febuxostat, a novel non-purine inhibitor of xanthine oxidase/xanthine dehydrogenase. Life Sci 2005;76:1835-47.

7. Komoriya K, Osada Y, Hasegawa M, Horiuchi H, Kondo $\mathrm{S}$, Couch RC, et al. Hypouricemic effect of allopurinol and the novel xanthine oxidase inhibitor TEI-6720 in chimpanzees. Eur J Pharmacol 1993;250:455-60.

8. Becker MA, Schumacher HR, Espinoza LR, Wells AF, MacDonald P, Lloyd E, et al. The urate-lowering efficacy and safety of febuxostat in the treatment of the hyperuricemia of gout: the CONFIRMS trial. Arthritis Res Ther 2010;12:R63.

9. Becker MA, Schumacher HR, MacDonald PA, Lloyd E, Lademacher C. Clinical efficacy and safety of successful longterm urate lowering with febuxostat or allopurinol in subjects with gout. J Rheumatol 2009;36:1273-82.

10. Schumacher HR Jr, Becker MA, Wortmann RL, Macdonald PA, Hunt B, Streit J, et al. Effects of febuxostat versus allopurinol and placebo in reducing serum urate in subjects with hyperuricemia and gout: a 28-week, phase III, randomized, double-blind, parallel-group trial. 
Arthritis Rheum 2008;59:1540-8.

11. Becker MA, Schumacher HR Jr, Wortmann RL, MacDonald PA, Eustace D, Palo WA, et al. Febuxostat compared with allopurinol in patients with hyperuricemia and gout. N Engl J Med 2005;353:2450-61.

12. Becker MA, Schumacher HR Jr, Wortmann RL, MacDonald PA, Palo WA, Eustace D, et al. Febuxostat, a novel nonpurine selective inhibitor of xanthine oxidase: a twenty-eight-day, multicenter, phase II, randomized, double-blind, placebo-controlled, dose-response clinical trial examining safety and efficacy in patients with gout. Arthritis Rheum 2005;52:916-23.

13. Wallace SL, Robinson H, Masi AT, Decker JL, McCarty DJ, Yü TF. Preliminary criteria for the classification of the acute arthritis of primary gout. Arthritis Rheum 1977;20:895-900.

14. Gray CL, Walters-Smith NE. Febuxostat for treatment of chronic gout. Am J Health Syst Pharm 2011;68:389-98.

15. Lee MH, Graham GG, Williams KM, Day RO. A benefit-risk assessment of benzbromarone in the treatment of gout. Was its withdrawal from the market in the best interest of patients? Drug Saf 2008;31:643-65.

16. Whelton A, Macdonald PA, Zhao L, Hunt B, Gunawardhana L. Renal function in gout: long-term treatment effects of febuxostat. J Clin Rheumatol 2011;17:7-13.

17. Bardin T. Current management of gout in patients unresponsive or allergic to allopurinol. Joint Bone Spine 2004;71:481-5. 